ISSN: 2224-0616

Int. J . Agril. Res. Innov. \& Tech. 7 (2): 7-17, December, 2017

Available online at http:// www.jjarit.webs.com

\title{
SCREENING OF DROUGHT-TOLERANT AND SENSITIVE GENOTYPES IN SOYBEAN (Glycine max L.) USING DIFFERENT MULTIVARIATE METHODS
}

\author{
S.H. Yahoueian" ${ }^{*}$, M.R. Behamta², H.R. Babaie ${ }^{3}$ and M. Mohammadibazargani4 \\ Received 2 June 2017, Revised 21 October 2017, Accepted 24 December 2017, Published online 31 December 2017
}

\begin{abstract}
The soybean is a crop of global importance, which cultivate in worldwide. However, the soybean is more susceptible to water shortages during germination and reproductive growth stages. Stress is an in ordinary physical process of environmental factors effects and it has traumatic ability, which causes unusual metabolism in plants, and it is possible; reduce plant product or causes plant death. Drought indices provide a measure of drought based on loss of yield under drought conditions in comparison to normal and have been used for screening drought tolerant genotypes. We cultivated Ten genotypes of soybean in the research field of seed and plant improvement institute in Karaj- Iran in 2015 June. The experimental design was a randomized block with three replicate in two separate field experiments for normal and stress conditions. We irrigated the normal experiment in 85\% field capacity and got 50\% filed capacity for stress conditions. Seventeen drought tolerance indices were calculated. Four methods were used to identify more resistant and more susceptible genotypes. After genotypes selection, we carried out experiment in green house with two selected genotypes. Results showed using the indices such as MP, GMP and STI, alone, cannot select a stable genotype and we have to use a combine of all indices or use indices that showed reduction and average yield, together. In second year, results showed that we had a true selection.
\end{abstract}

Keywords: Indices, Drought Tolerant, Soybean Genotypes.

${ }^{1}$ Department of Agriculture, Science and Research Branch, Islamic Azad University, Tehran, Iran.

${ }^{2}$ University of Tehran, Iran

${ }^{3}$ Seed and Plant Improvement Institute, Karaj, Iran

${ }^{4}$ Department of Medicinal plants, Agriculture Research Institute, Iranian Organization Research Science and Technology, Tehran, Iran.

*Corresponding author's email: hamidyahoueian@gmail.com (S.H. Yahoueian)

\section{Introduction}

The Soybean is a globally important crop, which cultivated as frequently crop in the worldwide. It used as one of the main sources of edible vegetable oil and high-protein livestock feed as well as for industrial purposes due to the high content of oil and protein in its seeds. Soybean plants also play an important role in crop diversification and benefit from the growth of other crops, enrichment nitrogen to the soil during crop rotation. Soybean has the most areas under culture in the world, among oil seed crops (Singh, 2010). It is a cheap nutrition resource, which can replace with portion of protein in the diet (Madhaj and Lake, 2013). However, among the leguminous family, soybean is most susceptible to water shortages during germination and the reproductive growth stages. Soybean is resilient to brief periods of drought, or water deficit, but the timing, duration, and severity of the stress plays a major role in determining the impact on yield. Indeed, large variation in water content of soil, lead to a significant decrease in biological N2 fixation (BNF) (Serraj et al., 1999). Stress is a no ordinary physical process of the environmental factors effects and it has traumatic ability, which causes unusual metabolism in plants, and it is possible, reduce output growth or plant death (Hekmatsho'ar, 1993). Changes in global climate behavior have revealed in an increase in extreme temperature related events such as drought, salinity, contamination and flooding of vast areas of the planet. About agricultural, these uncertain climatic scenarios are likely to cause biotic and abiotic stress increases, which must be dealt with through science and technology (Roveda-Hoyos and Fonseca-Moreno, 2011). Drought stress, which especially occurs in late vegetative stages, may cause significant yield losses, up to $40 \%$ in the bad year, and a reduction of seed quality in soybean (Sulieman and Tran, 2012). Iran is on the world's desert belt, and is considered as the arid and semiarid region. Average rainfall in the country is about $250(\mathrm{~mm})$ which is one third of 
average rainfall in the world, while 1.2 percent of the world's land is allocated to Iran. On the other hand, of 18.5 million hectares of agricultural lands, 6.2 million hectares (33.5 \%) are devoted to dry cultivation. About 1.2 million/ha of lands under dry cultivation, more than $400 \mathrm{~mm}$ rainfall will receive (Mohammadi et al., 2006).The increase in drought events in the last decade has caused production losses in recent harvests. This fact compels us to understand the drought tolerance mechanisms in soybean, considering its variability among commercial and developing cultivars (Vidal et al., 2012).Water stress is one of the most important factors limiting plant performance and yield worldwide (Boyer, 1982). Effects of water stress on plant physiology, including growth (McDonald and Davies, 1996), signaling pathways (Chaves et al., 2003), gene expression (Bray, 1997; 2002), and leaf photosynthesis (Lawlor and Cornic, 2002; Flexas et al., 2004), have studied, extensively. Terminal drought can reduce seed yields by 58-95\%. Reduce in pod production and grains filling are key factors, which affect final seed yield (Leport et al., 2006). Drought, also, increases effects of other stresses and several stresses create from that such as salinity and cold. Blum (1988) believes an environmental stress appears usually forms of shortages as water, nutrition and warmth. Drought and heat stress cause declines in: root growth, leaf water potential, cell membrane stability, photosynthetic rate, photochemical efficiency, as well as in carbohydrate aocumulation (Guttieri et al., 2001). Smirnoff (1993) has mentioned reactions leading active oxygen formation cells and the enzyme system, antioxidants and free radical scavengers, which minimize their damaging effect, will be covered in sufficient detail to provide a background for the consideration of these processes during water deficit. The speedy development of leaves reduces under drought conditions so the leaf size becomes smaller. In fact, early session stresses cause the soybean by limiting growth focuses all of the its energy to expand root. The most visible sign of soybean in response to drought stress is contrary leaves to reflect the light and this reaction cause water storage and decreasing temperature and photosynthesis rate and save the water (Shaun, 2012). Drought stress at later vegetative stages of development has similar results. Shoot growth is decreased or stopped, but roots can continue to grow. This evolutionary response in soybean allows the plant to search for additional water while having an overall low water use rate. Assuming adequate rainfall occurs again, soybean have the ability to initiate shoot growth, and shoot growth rate may be greater than that observed prior to the onset of drought stress. This is called compensatory growth. Short-term, moderate drought stress during the vegetative growth stages generally does not affect soybean yield. Conversely, long-term severe drought stress can cause irreversible plant cell death causing low growth yield. Seed yield is limited, particularly, when drought stress occurs during pod filling. The lack of fast screening techniques complicates Drought resistance breeding. It is an inability to create routinely defined and repeatable water stress conditions when most genotypes can evaluate efficiently (Ramirez-Vallejo and Kelly, 1998). Generally, different strategies have been proposed for the selection of relative drought tolerance and resistance. Therefore, some researchers have proposed selection under nonstress conditions (Betran et al., 2003), others have suggested selection in the target stress conditions (Ceccarelli and Grando, 1991) while, several of them have chosen the midway and believe in selection under both non-stress and stress conditions (Fisher and Maurer, 1978; Fernandez, 1992). Thus, drought indices, which provide a measure of drought based on yield loss under drought conditions in comparison to normal conditions, have been used for the screening drought tolerant genotypes (Mitra, 2001). These indices are based on either drought resistance or susceptibility of genotypes (Fernandez, 1992). Various quantitative criteria have been proposed to select genotypes based on their yield performance in stress and non-stress environments. Based on the indicators, genotypes are compared with irrigated and rain-fed conditions or with different levels of irrigations (Taghian and Abo-Elwafa, 2003). Fisher and Maurer (1978) considered two steps in drought resistance cultivar providing which is severe selection for grain yield at drought stress condition and at last, remain cultivars select in base of important physiologic traits and linked to grain yield. Depending on genotypes reactions to drought conditions and non-stress, they can divide into four separated groups. Group A, is genotypes which have the most yield in both environments. Donald (1968) proposed breeding should directly in order to create optimized type rather than attention to high yield, particularly but Evans (1973) suggested breeders must be attention to compatibility rather than idiotype. Amongst the issues, important in the breeding of yield, is attention to yield components and modify them. Here of, Sediyama et al. (1972) showed the number of pods per plant have a high correlation to yield and is the best scale for selection and the big size of seeds is a function of the number and size of grain production per unit of area. Purcell and King (1996) has reported bush high affected from drought stress, but have no correlation with yield. In addition, it has been proved, environmental factors, decrease the yield usually by reducing the seed number to the grain 
size. Since, the longer seed filling period causes increase the seed size, there is a positive relationship between yield and grain filling period. These reports proposed seed size as an important yield components and it impresses genetic differences of genotypes.

Drought indices, which provide a measure of drought based on loss of yield under droughtconditions in comparison to normal conditions, have been used for screening drought tolerant genotypes (Mitra, 2001). These indices are base on either drought resistance or susceptibility of genotypes (Fernandez, 1992). Hall (1993) defined drought resistance as the relative yield of a genotype compared to other genotypes subjected to the same drought stress. The drought susceptibility of a genotype is often measured as a function of the reduction in yield under drought stress (Blum, 1988). Rosielle and Hamblin (1981) defined stress tolerance (TOL) as the differences in yield between the stress (Ys), non-stress (Yp) environments, and mean productivity (MP) as the average yield of Ys and Yp. Fisher and Maurer (1978) proposed a stress susceptibility index (SSI) of the cultivar. Fernandez (1992) defined a new advanced index (STI = stress tolerance index), which can be used to identify genotypes that produce high yield under both stress and nonstress conditions. Other yield base estimates of drought resistance are geometric mean (GM), mean productivity (MP) and TOL. Breeders interested in relative performance often use the geometric mean since drought stress can vary in severity in a field environment after years (Ramirez-Vallejo and Kelly, 1998). Different researchers (Fernandez, 1992) have compared these indices and their genetic parameters have been studied (Golabadi et al., 2006). Mousavi et al. (2008) reported although STI and GMP can separate group A, but they have little emphasis on stability of yield between the two conditions. In this research, new indices have been proposed (ATI and SSPI) that are able to separate relative tolerant and non tolerant genotypes better than previous indices, along with a new index (SNPI) is able to separate group A from others and has an emphasis on high and stable yield in both environmental conditions. Abd-Mishani and J afari-Shabestari (1988) studied 35 Iranian wheat varieties to identify their drought resistance and found out there is a relationship between yield in drought stress condition and drought resistance index. They correlate about $71 \%$. They have proposed using STI and GMP for a selection of resistance to drought. Shafazadeh et al. (2004) studied 20 winter wheat genotypes on final season drought stress. They have declared indices such as STI, GMP and MP have a high positive correlation with yield and can identify drought tolerate genotypes having high yield. Since a large part of Iran's area is dry and semi dry climate and drought tolerant genotypes is important to deal with this limitative factor. Undoubtedly require a tool to infer genotype resistance, including resistance indices, two-dimensional and threedimensional distribution diagrams, can be useful in identifying these genotypes (Kazemi-Tabar et al., 2005). The numerous strategies are in the resistant genotype selection, that each, in turn, could have an efficiency of selection. The first strategy, the selection a high yield variety in optimum condition, is more efficient than selecting in abnormal condition. The second strategy, states that due to lack of the relationship between special morphological characters and resistance to drought, apparently, are directly used to improve resistance to drought conditions, because of the lack of the relationship between morphological strategy and drought resistance. The easiest selection method of drought tolerant varieties is selection base on their yield in stress condition. In third strategy, researchers, try to improve varieties have the lowest damage or lost of yield loss in moderate stress condition.

\section{Material and Methods}

The experiment was conducted in the experimental filed of the seed and plant improvement institute in Karaj-Iran at June 2016. A randomized block experimental design with three replications was used. The treatments included combinations of two water regimes, well-watered and drought, and ten genotypes of soybean. Drought treatment initiated at V4 phase. The soil moisture was maintained at 80$90 \%$ and $50 \%$ field capacity (FC) in well-watered and droughty conditions, respectively, until physiological maturity. Irrigated time was found by TDR (model 6050x1). At the end of the session, we harvested all genotypes and estimated their filed yield as tons per hectare.

Table 1. Name of cultivated genotypes.

\begin{tabular}{ll}
\hline Name of genotypes & Name of genotypes \\
\hline GN 2125 & Hcheston $\times$ L16/ 16 \\
Stresslnd $\times$ NMS3 & GN 2157 \\
D42.I9 & GN 3074 \\
D42 $\times$ Will. 82 & GN 2032 \\
Chleston $\times$ Mostn & D42.I4 \\
\hline
\end{tabular}

We used yield per hectare to calculate Seventeen drought tolerance indices. These indices included Stress susceptibility index (SSI), Stress tolerance index (STI), Geometric mean productivity (GMP), Tolerance (TOL), Harmonic means (HM), Mean production (MP), Yield index (YI), Drought resistance index (DRI), Yield stability index (YSI), Stress susceptibility percentage (SSPI), Stress non-stress production index (SNPI) and Abiotic tolerance index (ATI), which use the following relationships: 
(1) $\mathrm{SSI}=\frac{1-\left(\frac{Y_{g}}{Y_{p}}\right)}{1-\left(\frac{P_{s}}{Y_{p}}\right)}(2) \mathrm{STI}=\frac{Y_{2} \times Y_{s}}{\widetilde{F}_{p}^{2}}$

(3) $\mathrm{GMP}=\sqrt{Y_{p} \times Y_{S}}(4) \mathrm{MP}=\frac{Y_{p}+Y_{S}}{2}(5) \mathrm{TOL}=\mathrm{Y}_{\mathrm{p}}-\mathrm{Y}_{\mathrm{S}}$

(6) $\mathrm{HARM}=\frac{2 \times\left(\mathrm{r}_{\mathrm{p}} \times \mathrm{r}_{s}\right)}{Y_{\mathrm{p}}+\mathrm{Y}_{s}}(7) \mathrm{YI}=(\mathrm{Ys}) /(\mathrm{Ys})(8) \mathrm{YSI}=\mathrm{Ys} / \mathrm{Yp}$

(9) DI $=(\mathrm{Ys} \times(\mathrm{Ys} / \mathrm{Yp})) / \mathrm{Ys}(10)$ ATI $=\left[(\mathrm{Yp}-\mathrm{Ys}) /\left(\bar{Y}_{s} / \bar{Y}_{p}\right)\right]^{*}\left(\sqrt{\left.Y_{p} \times Y_{s}\right)}\right.$

(11) $\mathrm{SSPI}=(\mathrm{Yp}-\mathrm{Ys} / 2(\mathrm{Yp})) \times 100(12) \mathrm{SNPI}=(\mathrm{yp}+\mathrm{ys}) /(\mathrm{yp}-\mathrm{ys})]^{\wedge}(1 / 3) /\left(\mathrm{yp}^{*} \mathrm{ys} * \mathrm{ys}\right) \wedge 1 / 3$

(13) $\mathrm{SDI}=\frac{Y_{p}-Y_{S}}{Y_{p}}(14) \mathrm{DRI}=\frac{Y_{s}-\hat{Y}_{g}}{S_{E}}$

(15) $\mathrm{RDI}=(\mathrm{Ys} / \mathrm{Yp}) /(\mathrm{Ys} / \mathrm{Yp})$

Where, Ys and Yp represent a yield in stress and non-stress conditions, respectively. In addition, $\bar{Y}_{p}$ and $\bar{Y}_{s}$ are mean yield in stress and non-stress conditions, respectively (for all genotypes).

These indices use finding the most resistance and susceptible genotypes in some ways and finally, by combining the results of these ways.

To identify the most resistant and the most susceptible genotype, we used indices in biplot and ranking analysis. We compared the results of these two ways for selection of genotypes. In the first way, we ranked genotype values in each index. Therefore, the best value scored 1 and worst one scored 10. Finally, we calculated mean of scores and standard deviation for each genotype. We can select genotype with the lowest score and the lowest standard division, most resistance. Genotypes with the highest score and the lowest standard division have mentioned as susceptible to drought stress.

For clearly identifying, we used biplot analysis with obtained indices and calculated it by STATISTICA software for ten genotypes. Biplot chart divided into four sections and each section named with a word. Group A was containing the genotypes with high yield in stress and non-stress condition. The genotypes in-group $\mathrm{D}$ has the lowest, weak yield for both conditions. For group $B$, genotypes have strong and weak yield in nonstress and stress conditions, respectively, and for group C, genotypes are vice versa. Selected genotypes in biplot analysis were calculated for SSI indices and GMP and a chart was drawn which show distance of each genotype from mean of those. We calculated Cluster analysis for genotypes by the indices. Cluster method was wards and genotypes clustering were done by the $\sqrt{\frac{N}{2}}$. Lastly, STS index were used for comparing genotypes.

$\mathrm{STS}=\mathrm{MP}+\mathrm{STI}+\mathrm{GMP}+\mathrm{YI}+\mathrm{DRI}+\mathrm{YSI}-\mathrm{SSI}-\mathrm{TOL}-\beta$ (16)

\section{Second year:}

Two genotypes which were the most susceptible and the most resistant were cultured for second year, in two drought levels as normal and 50\% FC drought stress with 3 replication. We measured traits in greenhouse such as RWC, water loss rate, chlorophyll, in last fully expanded leaf. Chlorophyll was measured by spad. For measuring of water loss rate in leaf, we left the leaves in room temperature and every one hour measured their weight until fully became dry and calculated their water lose rate by drawing its variation weight by time charts.

\section{Results}

Estimation of drought resistance indices showed identifying of resistant varieties by one index could obtain contradictory results. We recognized most tolerant genotype based on all of the indices, as Farshadfar and Elyasi (2012), Naghavi et al. (2013) and Khalili et al. (2012). As the results showed (Table 2) the genotype D42.I9 has lowest rank, in base of ranking the genotypes, that showed as best genotypes but this genotype has in SDI, SSI and Tolrank 2. Genotype GN3074 has average rank 2.9 and standard deviation 2.86, so it is located in position 2. This genotype identifies as the most tolerate genotype base on TOL, SDI and SSI. The most susceptible and the weakest genotypes base on index ranking, is GN2032, which has rank 10 and standard deviation 1.77. This genotype has last rank which has shown, yield was weak in both conditions (Table 2).It has ranked 1, base on SSI and SDI to be the most sensitive (Table 2). This genotype showed a 70\% decrease in yield and has last rank on yield in normal and stress conditions. One region for lower yield per plant, in early maturing variety, is the short productivity duration and decrease in growth duration (Mohammadi et al., 2006). Genotype 2 (Stressland $\times$ NMSB/3) has been ranked 2 after GN2032, which its average 
was $8.1(\mathrm{STD}=2.03)$. This genotype does not have a suitable yield in stress and it has a large yield reduction. In terms of Fernandez (1992), it has been ranked 8 (Table 1). The most variations in ranking are about GN3074 (SDR=2.86) and it ranked second after D42.I9. This genotype yield has many changes and received to rank 2 in stress condition while has rank 8 in normal condition. It has the least SDI and show upper tolerance into the other genotypes. Biplot analysis (Chart 1) has shown, two first factors justified, $60.91 \%$ and $35.22 \%$ of variations, respectively. Biplot chart divided into the 4 zone. Genotype D42.I9 located in zone $\mathrm{A}$, this zone has high yield in both conditions, and on the other hand, genotypes GN 2032 and Charleston are in zone D. It has a poor yield in both conditions. The genotypes located in zone B have high yield in normal and weak production in stress condition. These genotypes do not have a superior rank in stress condition; however, they have good production in normal condition. They are Stressland $\times \mathrm{NMSB} / 3$, D42×Will.82, GN 2157 and D42.I4. It would be better select between these genotypes if it is not any suitable genotypes in D zone. Genotypes in D zone have lower yield potential, they have the worst ranks (Table 1), and if they have a muchreduced yield, we can select genotypes of this zone as a weakest genotype. In this zone, genotypes were Chaleston $\times$ Mostang/ 12 and GN2032, which have the most reduction yield. GN2032 has SDI $=0.703$ and SSI $=1.54$. If we consider the angle between the Yp and Ys (Chart1), GMp, Harm, MP and STI located between these two and it seems, they are as the best indices to separate genotypes which have high yield in stress and non stress conditions. Indices such as ATI, SSpi that align with Yp and have high correlation with the second component are able to separated genotypes in normal condition while indices such as DRI, YSI, YI, SSI and SDI are aligned with Ys and the first component. Genotypes 8, 1 and 6 are the most tolerant genotypes, Base on Ys aligned indices. Consideration of important indices and yield stress, non-stress condition, can help us to find most tolerant genotypes. For this issue can draw the some interaction between indices and compare the genotypes by selecting indices. As it is seen, 2D charts of difference SSI and GMP from their means (Chart 2) can divide genotypes to 4 groups. Genotype land 8 located in the same group and have a yield higher than average and have lower SSI than average. Genotype 9 has the greatest difference from average in both indices and it locates in low yield and sensitive section of the chart. In this area, locate genotype 2 and 5, too, but have a higher yield of 9. Yousefi (2015) found that MP, GMP, MH and STI are desirable indices for selection, drought resistant genotypes and had a strength correlation with two growth conditions and can use for selecting in barely genotypes with high drought resistance and high grain yield. Khodarahmpour et al. (2011) showed that the STI and GMP indices were the more accurate criteria for selection of heat tolerant and high yielding genotypes. Eivazi et al. (2013) indicated that MP index was the best criterion for selecting genotypes with high grain yield at both well watered and drought stressed conditions. According to Ganjali et al. (2009), there were positive and highly significant correlations among MP, GMP, STI and HARM with yield in stressed and non-stressed conditions. Abiotic stress tolerance is a key component and in some cases the major factor in improving yield in crops (Tollenaar and Wu, 1999). Drought stress is considered as one of the most visible factors, which affect grain yield, and some of the constituents of the grain oil of sunflower (Razi and Assad, 1999; Ali et al., 2009). Cluster analysis of genotypes was done for indices by wards (Chart 3) and was used to classify genotypes and verification results of biplot and revealing the difference between groups and genotypes. Cluster analysis showed that genotypes 6, 1 and 8 stand in a group which has the lowest $\overline{S D I}(\mathrm{SDI}=\% 20)$ and group average yield was1.6 tons/ ha in normal and1.3 tons/ha in stress condition. Group 9,5,7 are located in the far distance to this group and have the lowest STi $(\mathrm{STI}=0.4)$ and SSi more than 1 and this group is as the most sensitive groups, of course, group 4 and 2 has a high SSI and SDI, too but because of high mean yield is not suited to select. Cluster analysis results confirm biplot results. An average of the SSI in groups has shown groups 5-7-9 is the most sensitive and average of Fisher and Morer index has showed group 1-6-8 as the most tolerate. If we would consider the number of groups of formula $\sqrt{\frac{N}{2}}$, decrease the number of groups in 2 that the new formed group has means between two groups of 2-4 and 3-10-5-9-7 and SSI of average new group showed sensitivity STS (Chart 4) index can separated genotypes as well as other methods and can useful because of convenience and accuracy. This index separated susceptible, tolerat genotypes, introduced GN3074 as the most tolerant genotypes. GN2032 and Stressland $\times$ NMS3 as the most susceptible genotypes. 


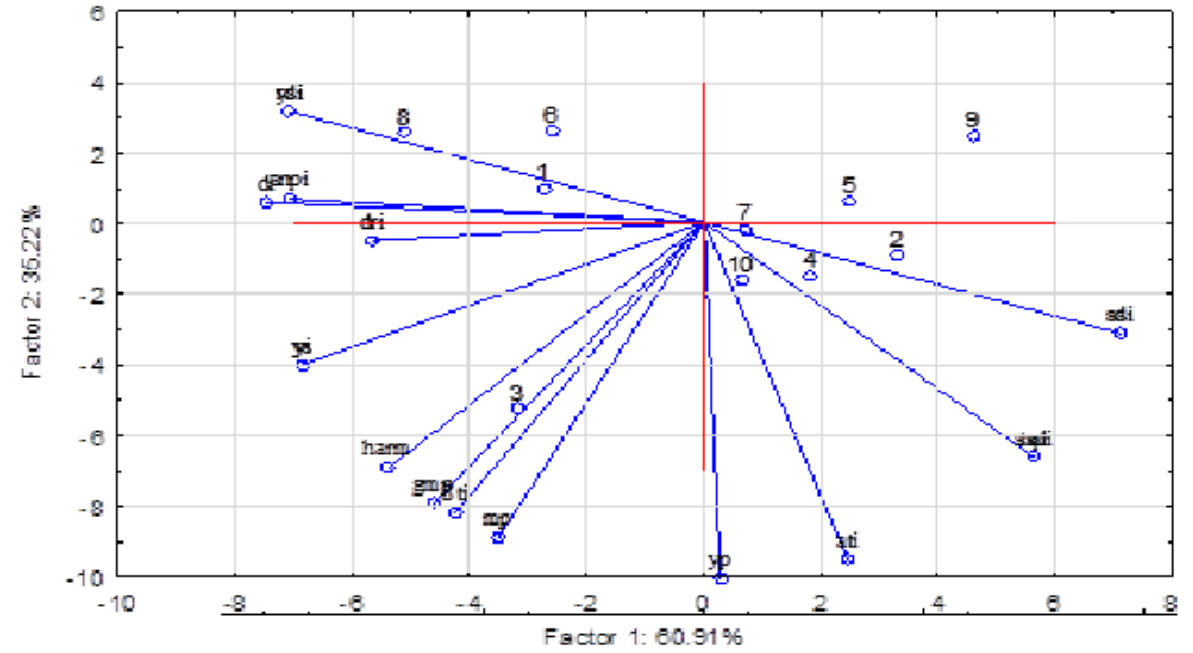

Chart 1. Biplot analysis of yield by drought tolerant indices.

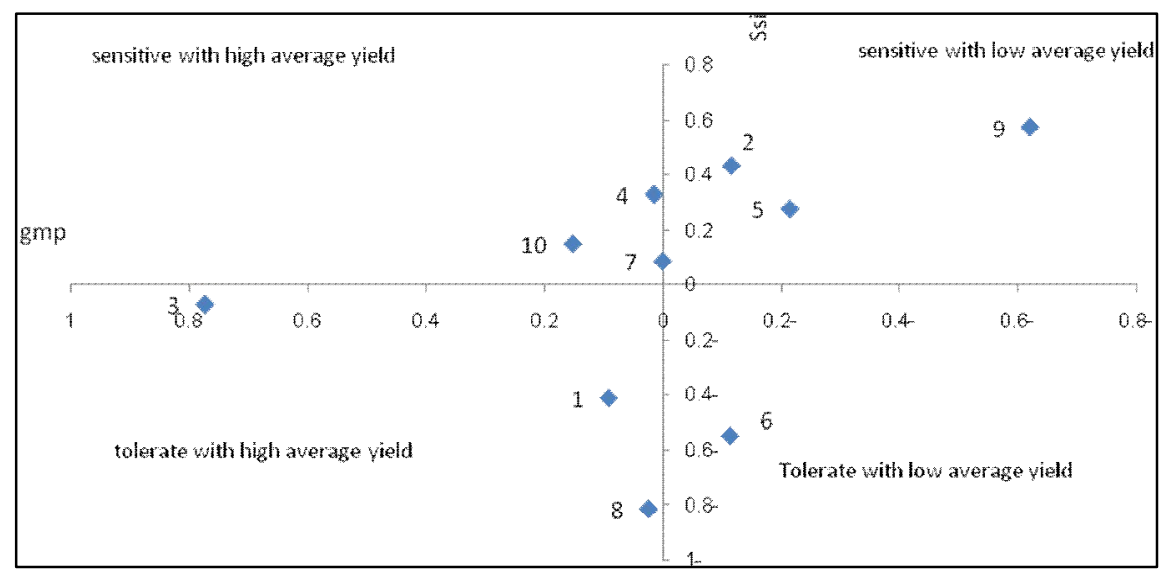

Chart 2. Genotypes difference from average between SSI and GMp.

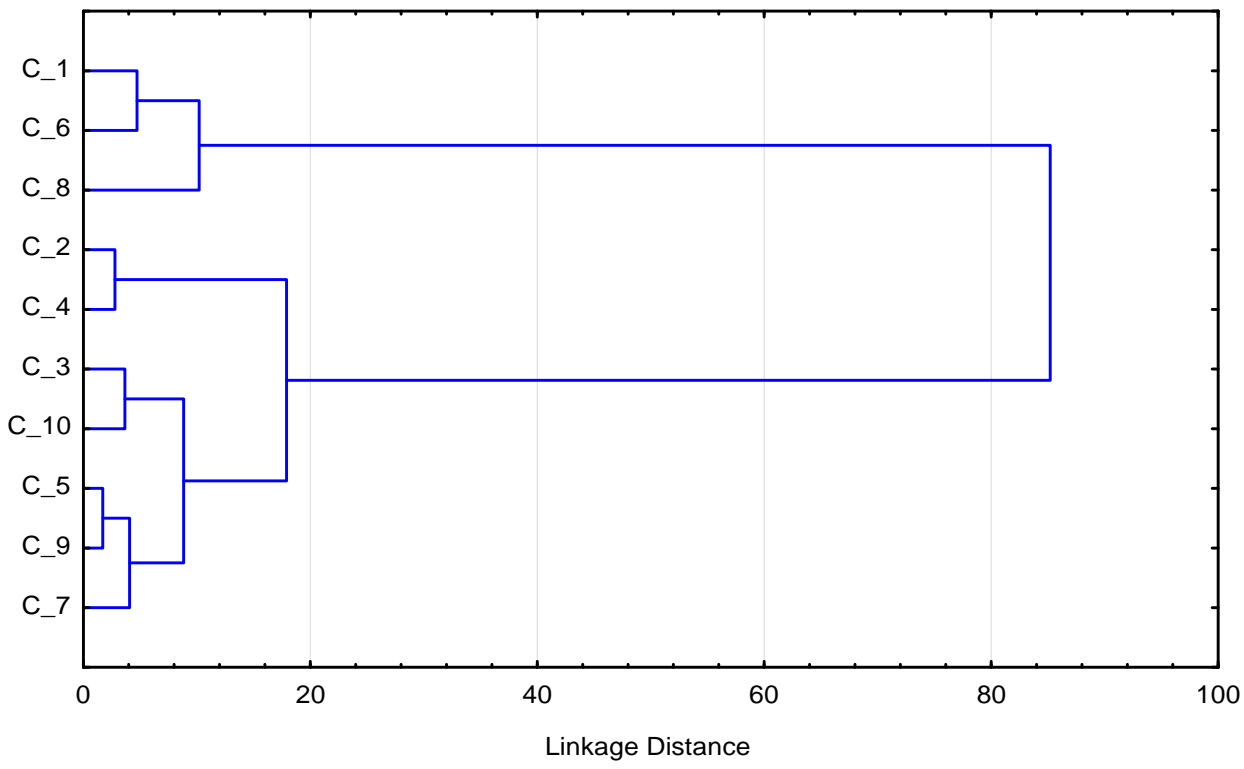

Chart 3. Cluster analysis of genotypes by drought indices in wards method. 
Table 2. Genotypes ranking in drought tolerance indices.

\begin{tabular}{|c|c|c|c|c|c|c|c|c|c|c|c|c|c|c|c|c|c|c|c|}
\hline & $Y p$ & Ys & Tol & $\mathrm{Mp}$ & Gmp & Harm & Sdi & Sti & Ssi & Dri & YI & DI & YSI & Sspi & Rdi & SNPI & ATI & $\bar{R}$ & SDR \\
\hline GN 2125 & $7_{(1.79)}$ & $3_{(1.33)}$ & $3_{(0.45)}$ & $4_{(1.56)}$ & $3_{(1.54)}$ & $2_{(1.53)}$ & $3_{(0.254)}$ & $3_{(0.599)}$ & $3_{(0.56)}$ & $4_{(0.56)}$ & $3_{(1.23)}$ & $3_{(0.917)}$ & $3_{(0.746)}$ & $3_{(12.69)}$ & $3_{(1.37)}$ & $3_{(4.67)}$ & $8_{(0.38)}$ & $3 / 6$ & $1 / 54$ \\
\hline Stressland $\times$ NMS $/ 3$ & $4_{(2,22)}$ & $9_{(0.8)}$ & $10_{(1.42)}$ & $6_{(1.51)}$ & $8_{(1.34)}$ & $8_{(1.18)}$ & $9_{(0.639)}$ & $8_{(0.449)}$ & $9_{(1.4)}$ & $10_{(-1.46)}$ & $9_{(0.74)}$ & $9_{(0.268)}$ & $9_{(0.361)}$ & $10_{(39.73)}$ & $9_{(0.66)}$ & $9_{(1.74)}$ & $3_{(1.03)}$ & $8 / 1$ & $2 / 03$ \\
\hline D42.I9 & $1_{(2.9)}$ & $1_{(1.71)}$ & $8_{(1.19)}$ & $1_{(2.3)}$ & $1_{(2.23)}$ & $1_{(2.15)}$ & $4_{(0.41)}$ & $1_{(1.245)}$ & $4_{(0.9)}$ & $2_{(1.01)}$ & $1_{(1.58)}$ & $2_{(0.931)}$ & $4_{(0.59)}$ & $8_{(33.21)}$ & $4_{(1.08)}$ & $2_{(5.73)}$ & $1_{(1.43)}$ & $2 / 7$ & $2 / 34$ \\
\hline D42 $\times$ Will. 82 & $2(2.3)$ & $7_{(0.94)}$ & $9_{(1.36)}$ & $3_{(1.62)}$ & $5_{(1.47)}$ & $6_{(1.33)}$ & $8_{(0.592)}$ & $5_{(0.541)}$ & $8_{(1.3)}$ & $3_{(0.71)}$ & $7_{(0.86)}$ & $7_{(0.351)}$ & $8_{(0.408)}$ & $9_{(38.08)}$ & $8_{(0.75)}$ & $7_{(2.18)}$ & $2_{(1.08)}$ & $6 / 1$ & $2 / 37$ \\
\hline Chleston $\times$ Mostng/12 & $6_{(1.8)}$ & $8_{(0.81)}$ & $5_{(1.07)}$ & $8_{(1.35)}$ & $9_{(1.24)}$ & $9_{(1.14)}$ & $7_{(0.568)}$ & $9_{(0.385)}$ & $7_{(1.25)}$ & $9_{(-1.08)}$ & $8_{(0.75)}$ & $8_{(0.324)}$ & $7_{(0.432)}$ & $5_{(29.95)}$ & $7_{(0.79)}$ & $8_{(1.77)}$ & $6_{(0.72)}$ & $7 / 4$ & $1 / 33$ \\
\hline Hachson $\times$ L16/16 & $10_{(1.49)}$ & $4_{(1.2)}$ & $2_{(0.29)}$ & $8_{(1.35)}$ & $7_{(1.34)}$ & $6_{(1.33)}$ & $2_{(0.192)}$ & $7_{(0.451)}$ & $2_{(0.42)}$ & $5_{(0.41)}$ & $4_{(1.11)}$ & $4_{(0.896)}$ & $2_{(0.808)}$ & $2_{(8.01)}$ & $2_{(1.48)}$ & $4_{(4.50)}$ & $9_{(0.20)}$ & $4 / 7$ & $2 / 69$ \\
\hline GN 2157 & $5_{(2.02)}$ & $6_{(1.05)}$ & $4_{(0.97)}$ & $5_{(1.53)}$ & $6_{(1.45)}$ & $5_{(1.38)}$ & $5_{(0.481)}$ & $6_{(0.53)}$ & $5_{(1.05)}$ & $8_{(-0.53)}$ & $6_{(0.96)}$ & $6_{(0.501)}$ & $5_{(0.519)}$ & $4_{(27.11)}$ & $5_{(0.95)}$ & $6_{(2.64)}$ & $5_{(0.76)}$ & $5 / 4$ & $0 / 94$ \\
\hline GN 3074 & $8_{(1.53)}$ & $2_{(1.42)}$ & $1_{(0.11)}$ & $7_{(1.48)}$ & $4_{(1.48)}$ & $4_{(1.48)}$ & $1_{(0.07)}$ & $4_{(0.548)}$ & $1_{(0.15)}$ & $1_{(1.08)}$ & $2_{(1.31)}$ & $1_{(1.22)}$ & $1_{(0.93)}$ & $1_{(3.02)}$ & $1_{(1.70)}$ & $1_{(9.22)}$ & $10_{(0.08)}$ & $2 / 9$ & $2 / 86$ \\
\hline GN 2032 & $9_{(1.52)}$ & $10_{(0.45)}$ & $5_{(1.07)}$ & $10_{(0.99)}$ & $10_{(0.83)}$ & $10_{(0.7)}$ & $10_{(0.703)}$ & $10_{(0.174)}$ & $10_{(1.54)}$ & $6_{(-0.23)}$ & $10_{(0.42)}$ & $10_{(0.124)}$ & $10_{(0.297)}$ & $6_{(30.05)}$ & $10_{(0.54)}$ & $10_{(0.76)}$ & $7_{(0.48)}$ & $9 / 0$ & $1 / 77$ \\
\hline D42.I4 & $3_{(2.29)}$ & $5_{(1.12)}$ & $7_{(1.17)}$ & $2_{(1.71)}$ & $2_{(1.6)}$ & $3_{(1.51)}$ & $6_{(0.5)}$ & $2_{(0.647)}$ & $6_{(1.12)}$ & $7_{(-0.47)}$ & $5_{(1.04)}$ & $5_{(0.588)}$ & $6_{(0.49)}$ & $7_{(32.68)}$ & $6_{(0.91)}$ & $5_{(2.90)}$ & $4_{(1.01)}$ & $4 / 8$ & $1 / 79$ \\
\hline
\end{tabular}

Note: Number in parentheses is the value of the index for each genotype. 


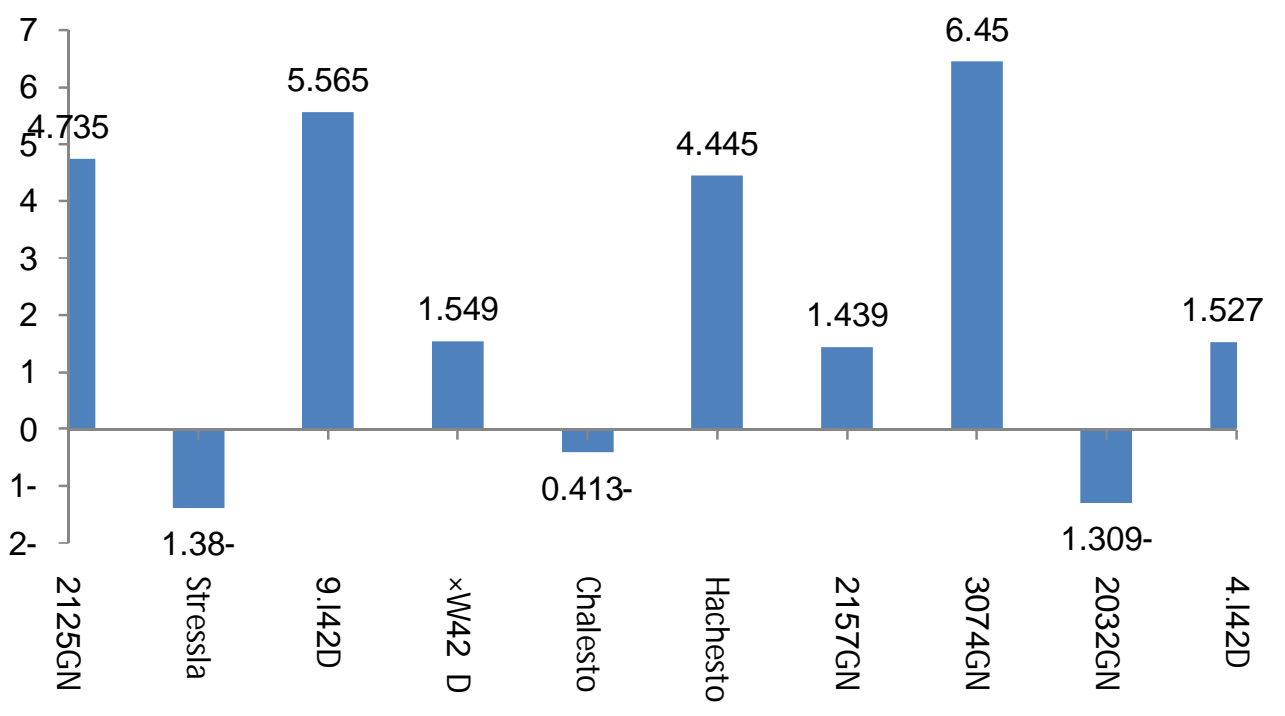

Chart 4. Comparison of Genotypes by STS Index.

\section{Second year}

In second year results showed traits were damaged and these damages were significant in $5 \%$ or $1 \%$ drought stress could increase the speed of drying leaves. Rate of water loss from leaves was the same and non-significant in both genotypes in normal condition. With increasing stress times, GN2032 (sensitive genotype), more rapidly lost its leaf water and this increase was observed on seventh day of the first sampling time and it was significant in $99 \%$ but it was not significant in tolerant genotype (GN-3074) in second sampling sensitive genotypes increased its water loss rate more than first time and it was a significant increase in $95 \%$ and in third sampling, water lose rate increased to 0.47 which had the most difference to normal condition but in tolerant genotype was little difference and non significant. These results showed tolerant genotypes can hold water for more times. Water loss rate increased more than 2 times in sensitive genotype in 21 days after started stress whiles it increased 1.5 times in tolerant genotype. Interestingly enough, an increase in the rate of water loss in sensitive genotype at sampling time on the seventh day was remarkable and was 1.8 times compared to normal condition but it was 1.3 times in tolerant genotype. Results showed rate of water loss was lower slope in tolerant genotype. Chlorophyll content increased to 14 days but in 21 day, decreased. The results showed that the plant so far been able to reduce the amount of water in the cell and increase the cell concentration has increased chlorophyll content.

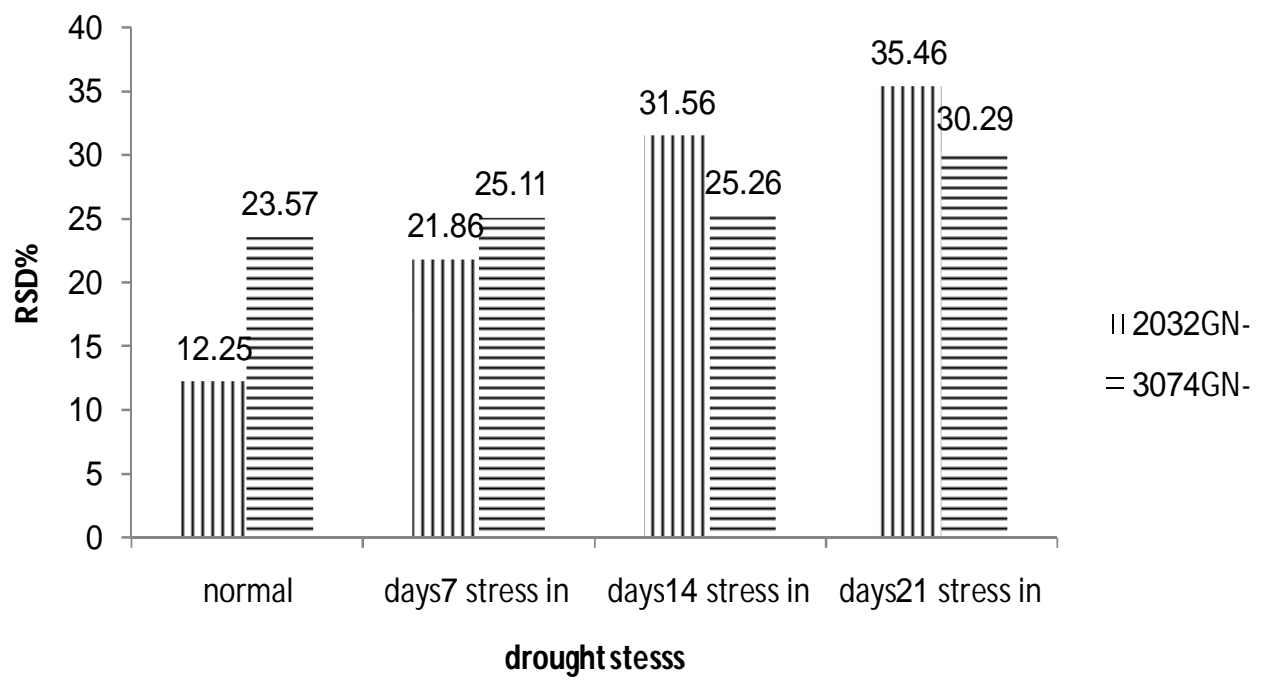

Chart 5. Comparison between genotypes in stress factors for leaf related saturated deficient by DMRT $\leq 5 \%$. 


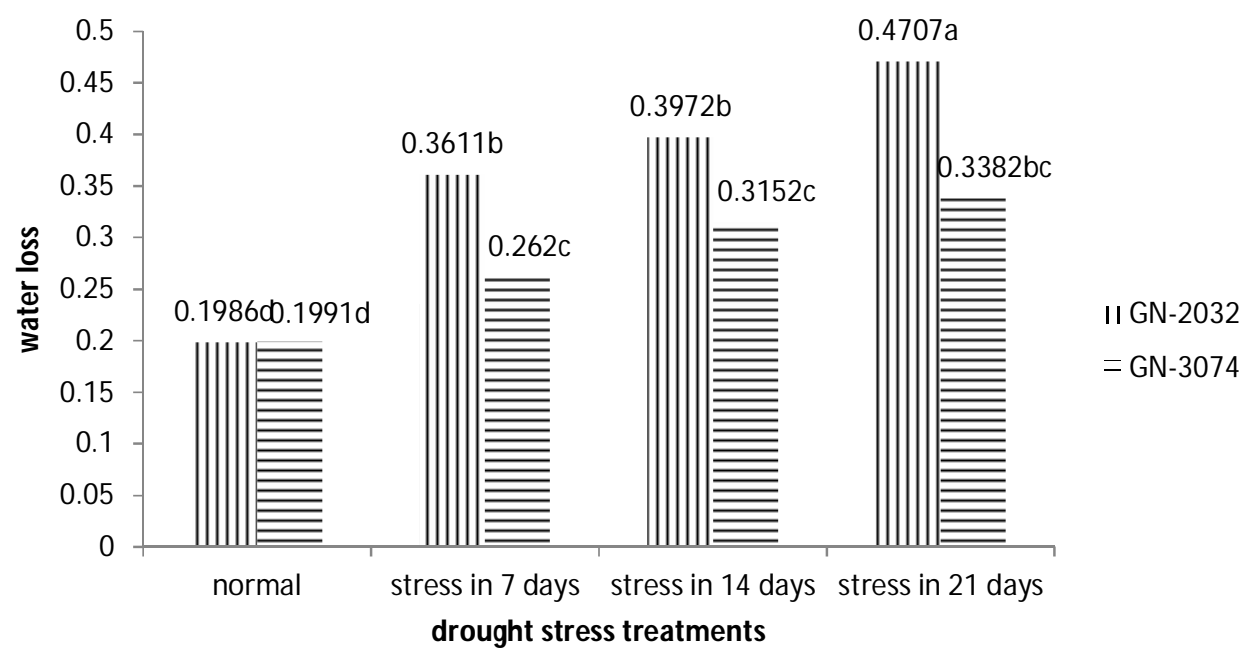

Chart 6. Comparison between genotypes in stress factors for leaf water loss rate by DMRT $\leq 5 \%$.

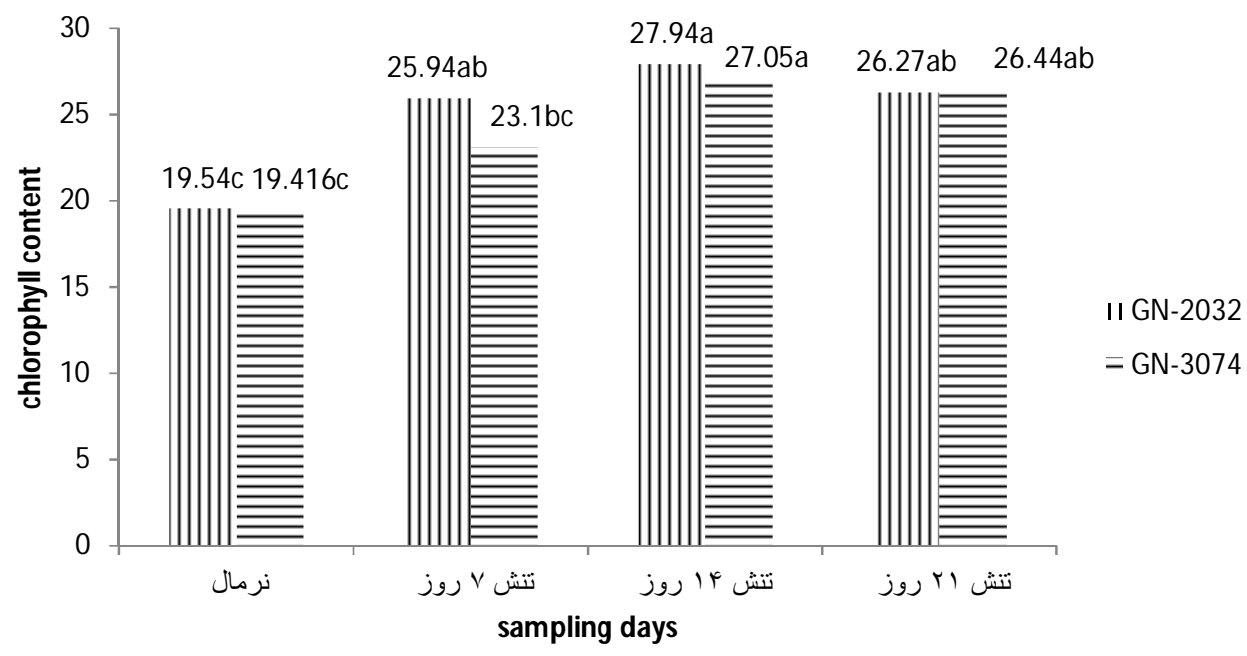

Char 7. Comparison between genotypes in stress factors for chlorophyll content by DMRT $\leq 5 \%$.

\section{Discussion}

Plant breeders seek to introduce varieties that have a good yield in different environments. Selection of variety which is good in all environmental conditions, have a problem because of Interaction between environment and genotypes and this interaction was causing researchers follow varieties that in different conditions are able to maximum of facilities. The GMP has lower sensitivity when Ys and Yp have high different, but at this time MP is biased towards Yp. GMP is able to separate group A between all groups accordingly, Fernandez (1992) established STI index based on GMP. Since, more stable genotypes have higher STI, it expected using this index, we can separate genotype group
A of the other groups. Najafian (2009) in a study on 291 wheat lines and 2 normal and stress condition, STI and GMP is more appropriate for selection of high yield lines in both conditions. Shiry et al. (2010) applied 3 different drought treats on 24 genotypes of wheat and expressed indices as STI and GMP have a superiority into other indices. Due to increase in indices such as STI and GMP, interfere with Yp, it is better, these indices use with indices that show a yield reduction in stress condition to normal. Mousavi et al. (2008) reported indices such as ATI or SSPI select genotypes especially on the basis of yield stability, while, select from the SNPI index is based on two characteristics simultaneously, 
namely yield stability as well as high YP and YS (with more emphasis on high YS than high YP) so, this index has a very strong and significant positive correlation with Ys in both data sets. In this study, we have searched a genotype, which have stability and high yield and just using indices such as STI and GMP or MP can't help us to find stable genotypes thus it is better these indices, use with indices that show stability and yield reduction.

\section{References}

Abd-Mishani, S. and Jafari-Shabestari, J. 1988. Evaluation of wheat cultivars for drought resistance. Iranian J. Agril. Sci. 19 (1\&2): 37-43.

Ali, Q., Ashraf, M. and Anwar, F. 2009. Physicochemical attributes of seed oil from drought stressed sunflower (Helianthus annuus L.) plants. Int. J. Fats Oils (Grasas y Aceites) 60(5): 475-481.

Betran, F., Beck, J.D., Banziger, M. and Edmeades, G.O. 2003. Genetic analysis of inbred and hybrid grain yield under stress and non-stress environments in tropical maize. Crop Sci. 43: 807-817.

Blum, A. 1988. Plant breeding for stress environment .CRC press, Bocaraton, USA. $223 \mathrm{p}$.

Boyer, J.S. 1982. Plant productivity and environments. Sci. 218: 443-448.

Bray, E. 1997. Plant responses to water deficit. Trends Plant Sci. 2: 48- 54.

Bray, E. 2002. Abscisic acid regulation of gene expression during water deficit stress in the era of the Arabidopsis genome. Plant Cell Environ. 25: 153- 161.

Ceccarelli, S. and Grando, S. 1991. Selection environment and environmental sensitivity in barley. Euphytica. 57(2): 157-161.

Chaves, M.M., Morocco, J.P. and Pereim, J.S. 2003. Understanding plant responses to drought from genus to whole plant. Func. Plant Biol. 30: 326-334.

Donald, C.M. 1968. The design of wheat idiotype. pp. 377-387. In: proc, $3^{\text {rd }}$ International Wheat Genetic Symp. Canberra.

Eivazi, A.R., Mohammadi, S., Rezaei, M., Ashori, S. and Hossien Pour, F. 2013. Effective selection criteria for assessing drought tolerance indices in barley (Hordeum vulgare L.) accessions. Int. J. Agron. Plant Prod. 4 (4): 813-821.

Evans, A.M. 1973. Commentary on plant architecture and physiological efficiency in the field bean. pp. 279-286. In: D. Wall (ed.), Potential of Field Beans and other Food Legumes in Latin America, CIAT, Cali, Colombia.
Farshadfar, E. and Elyasi, P. 2012. Screening quantitative indicators of drought tolerance in bread wheat (Triticum aestivum L.) landraces. Europ. J. Exp. Biol. 2(3): 577584.

Fernandez, G.C. 1992. Effective selection criteria for assessing plant stress tolerance. pp. 257270. In: Kuo, C.G.C. eds. Proceedings of the International symposium on adaptation of vegetable and other food crops to temperature water stress. Taiwan. 13-18, August, 1992.

Fisher, F.A. and Maurer, R. 1978. Drought resistance in spring wheat cultivars. I. grain yield responses. Australian J. Agril. Res. 30: 1001-1020.

Flexas, J., Bota, J., Loreto, F., Cornic, G. and Sharkey, T.D. 2004. Diffusive and metabolic limitations to photosynthesis under drought and salinity in C3 plants. Plant Biol. 6: 269279.

Ganjali, A., Bagheri, A. and Porsa, H. 2009. Evaluation of chickpea (Cicer arietinum L.) germplasm for drought resistance. J. Agron. Res. Iran 7(1): 183-194.

Golabadi, M., Arzani, A. and Maibody, S.A.M. 2006. Assessment of drought tolerance in segregating populations in durum wheat. African J. Agril. Res. 5: 162- 171.

Guttieri, M.J., Stark, J.C., Brien, K. and Souza, E. 2001. Relative sensitivity of spring wheat grain yield and quality parameters to moisture deficit. Crop Sci. 41: 327-335.

Hall, A.E. 1993. Is dehydration tolerance relevant to genotypic differences in leaf senescence and crop adaptation to dry environments? In: Plant Responses to cellular dehydration during environmental stress. (Eds.): T.J. Close and E.A. Bray, pp. 1-10.

Hekmatsho'ar, H. 1993. Plant physiology in extreme conditions. Niknampub, print 1.

Kazemi-Tabar, S.K., Samerand, B., Fotoohi, K. and Rezaei, M. 2005. Identification of drought resistant Genotypes in Sunflower (Heliantus annus L.) by drought tolerance indices 2D and 3D charts. Iran Agril. Sci. J. 1(38): 357-366.

Khalili, M., Naghavi, M.R., Pour Aboughadareh, A.R. and Talebzadeh, J. 2012. Evaluating of drought stress tolerance based on selection indices in spring canola cultivars (Brassica napus L.). J. Agril. Sci. 4(11): 78-85.

Khodarahmpour, Z., Choukan, R., Bihamta, M.R. and Majidi Hervan, E. 2011. Determination of the best heat stress tolerance indices in maize (Zea mays L.) inbred lines and hybrids under Khuzestan province conditions. Iranian J. Crop Sci. 13: 111-121. 
Lawlor, D.W. and Cornic, G. 2002. Photosynthetic carbon assimilation and associated metabolism in relation to water deficits in higher plants. Plant Cell Environ. 25: 275- 294 .

Leport, L., Turner, N.C., Davies, S.L. and Siddique, K.H.M. 2006. Variation in pod production and abortion among chickpea cultivars under terminal drought. European J. Agron. 24: 236- 246.

Madhaj, A. and Lake, S. 2013. Soybean. Azad Islamic University of Khozestan pub. Iran. p.159.

Mcdonald, A.J.S. and Davies, W.J. 1996. Keeping in touch: Response of whole plant to deficits in water and nitrogen supply. Advance in Bot. Res. 22: 229-300.

Mohammadi, A., Ahmadi, J . and Habibi, D. 2006. Drought tolerance Selection indices in wheat. Iran Agril. Breeding J. 1: 47-62.

Mitra, J. 2001. Genetics and genetic improvement of drought resistance in crop plants. Current Sci. 80: 758-762.

Mousavi, S.S., YazdiSamadi, B. Naghavi, M.R., Zali, A.A., Dashti, H. and Pourshahbazi, A. 2008. Introduction of new indices to identify relative drought tolerance and resistance in wheat genotypes. DESERT Online at http://jdesert.ut.ac.ir DESERT 12: 165-178.

Najafian, G. 2009. Drought tolerance indices, their relationship parameter of application in wheat breeding program. Middle Eastern and Russian J. Plant Sci. Biotech. 3: 25-34.

Naghavi, M.R., Pour Aboughadareh, A. and Khalili, M. 2013. Evaluation of Drought Tolerance Indices for Screening Some of Corn (Zea mays L.) Cultivars under Environmental Conditions. Not. Sci. Biol. 5(3): 388-393.

Purcell, L.C. and King, C.A. 1996. Drought and nitrogen source effects on nitrogen nutrition, seed growth, and yield in soybean. J. Plant Nutr. 19: 969-993.

Ramirez-Vallejo, P. and Kelly, J.D. 1998. Traits related to drought resistance in common bean. Euphytica. 99: 127-136.

Razi, H. and Assad, M.T. 1999. Comparison of selection criteria in normal and limited irrigation in sunflower. Euphytica. 105: 8390.

Rosielle, A. and Hamblin, J. 1981. Theoretical aspects of selection for yield in stress and non- stress environment. Crop Sci. 21: 943946.
Roveda-Hoyos, G. and Fonseca-Moreno, L.P. 2011. Proteomics: a tool for the study of plant response to abiotic stress. Agronomía Colombiana. 29(2): 221-230.

Sediyama, T., Cardoso, A.A. and Viera, C. 1972. Test preliminaries sobreosefetios do retardamentos da colheitadaasoja cultivar vicoja rev. Series 19: 306-310.

Serraj, R., Sinclair, T.R. and Purcell, L.C. 1999. Symbiotic $\mathrm{N}_{2}$ fixation response to drought . J. Exp. Bot. 50: 143- 155.

Shafazadeh, M.K., Yazdansepas, A., Amini, A. and Ghannadha, M.R. 2004. Study of Terminal Drought Tolerance in Promising Winter and Facultative Wheat Genotypes using Stress Susceptibility and Tolerance Indices. Seed and Plant. 20(1): 57-71.

Shaun, N.C. 2012. Signs of Drought Stress in Soybean, Casteel, Purdue University. p.5.

Shiry, M.R., Valizadeh, M., Majidi Heravan, I., Sanjary, A. and Eshgi, A. 2010. Evaluation of drought tolerance indices in bread wheat. Crop Prod. J. 3 (3): 143-161.

Singh, G. 2010. The soybean, botany, production and uses. Punjab university, India. p. 512.

Smirnoff, N. 1993. The role of active oxygen in the response of plants to water deficit and desiccation. New Phytol. 125: 27- 58.

Sulieman, S. and Tran, L.S. 2012. Asparagines: an amide of particular distinction in the regulation of symbiotic nitrogen fixation of legumes. Crit. Rev. Biotech. 33: 309-327.

Tollenaar, $\mathrm{M}$. and $\mathrm{Wu}, \mathrm{J}$. 1999. Yield improvement in temperate maize is attributable to greater stress tolerance. Crop Sci. 39: 1597-1604.

Taghian, A.S. and Abo-Elwafa, A. 2003. Multivariate and RAPD analyses of drought tolerance in spring wheat (Triticum aestivum L.). Assiut J. Agric. Sci. 34: 1-24.

Vidal R.O., Nascimento, L.C.D., Maurício Costa Mondego, J., Amarante Guimarães Pereira, G. and Falsarella Carazzolle, M. 2012. Identification of SNPs in RNA-seq data of two cultivars of Glycine max (soybean) differing in drought resistance. Genet. Mol. Biol. 35: 331- 334 .

Yousefi, B. 2015. Evaluation of genetic variations for drought tolerance in some advance lines of barley (Hordeum vulgare). Int. J. Farm. Allied Sci. 4(3): 177-184. 